\title{
И.С. Астафурова
}

Владивостокский государственный университет экономики и сервиса

ВлаАивосток. Россия

\section{Кластер судостроения и судоремонта Приморского края: перспективы и возможности}

\begin{abstract}
В настоящее время наблюдается стагнация российской экономики, а в некоторых отраслях - рецессия, А^я экономического развития России требуется разработка путей устойчивого развития как в периоА финансового кризиса, так и в периоды роста. Исследования, обусловленные необходимостью формирования эффективной стратегии российского судостроения и судоремонта на Аальнем Востоке, проблема обеспечения конкурентного развития судостроения и судоремонта на территории Аальневосточного федерального округа (АФО), в частности, Приморского края, в настоящее время приобретают особую значимость. А^я Аальнего Востока морской транспорт, судостроение и смежные виАы экономической Аеятельности яв^яются приоритетными и представ^яют собой направление, связанное с рыбным хозяйством. Поэтому перспективы развития судостроительной и судоремонтной отраслей Приморья актуальны Аля повышения конкурентоспособности предприятий этой сферы экономической деятельности Аля Аостижения статуса России как мировой державы. Судостроение и судоремонт в АФО имеют важнейшее народнохозяйственное значение Аля экономики страны в целом. Географическое положение региона, его значимость в отношениях с Китаем, Японией, Кореей не вызывают сомнения, оценка зарубежных моделей партнерства, взаимодействие частного и государственного секторов экономики должны быть комплексными. ОАной из приоритетных задач является организация преобразований в судоремонте и судостроении, в том числе и инновационных, ориентированная на успешное Аостижение жизненного цикла плана. Это позволяет обозначить основные этапы реализации кластерной политики в Приморье, руководствуясь "Методическими рекомендациями по реализации кластерной политики в субъектах Российской Федерации". В связи с этим представляется структура кластера как стимулирующая база Аля Аальнейшего развития судостроения и судоремонта в Приморском крае.
\end{abstract}

Ключевые слова и словосочетания: кластер, судостроение, судоремонт, конкурентоспособность, веАомственный, научный, производственный, единый центр ответственности, финансирование, алгоритм, потенциал.

\section{I.S. Astafurova}

Vladivostok State University of Economics and Service

Vladivostok. Russia

\section{Cluster of shipbuilding and ship repair in Primorsky Region: prospects and opportunities}

Currently, there is a stagnation in the Russian economy, and in some industries - a recession, for the economic development of Russia requires the development of ways for sustainable development, both during the financial crisis and during periods of growth. Studies, due to the need to form an effective strategy of Russian shipbuilding and ship repair in the Far East, the problem of ensuring the competitive development of shipbuilding and ship repair in the Far Eastern Federal District (and Far Eastern Federal District), and in

Астафурова Ирина Сергеевна - канд. экон. наук, доцент кафедры экономики; e-mail: Irina.Astafurova@vvsu.ru. Astafurova Irina Sergeevna - Ph.D., Associate Professor. 
Primorsky Region in particular, is now becoming particularly relevant. For the Far East, marine transport, shipbuilding and related economic activities are priority areas of the economy and represent a direction related to fisheries. Therefore, the prospects for the development of the shipbuilding and ship repair industries of Primorye are an actual basis for increasing the competitiveness of enterprises in these areas, as the basis for achieving the status of Russia as a world power, shipbuilding and ship repair for the DFO has the most important national economic importance for the country's economy as a whole. The geographic location of the region, its importance in relations with China, Japan, Korea is beyond doubt, the evaluation of foreign partnership models, interaction of private and public sectors of the economy should be comprehensive. One of the urgent tasks is the organization of transformations in ship repair and shipbuilding, including innovative ones, oriented to the successful achievement of the life cycle of the plan. This allows us to identify the main stages in the implementation of cluster policy in Primorye, guided by the "Methodological Recommendations for the Implementation of Cluster Policy in the Subjects of the Russian Federation". On this basis, the structure of the cluster is presented as a stimulating base for the further development of shipbuilding and ship repair in Primorsky Region.

Keyword: cluster, shipbuilding, ship repair, competitiveness, departmental, scientific, production, single responsibility center, financing, algorithm, potential.

Широкие возможности для развития кластерных проектов открывает использование потенциала особых экономических зон технико-внедренческого, промышленно-производственного, туристско-рекреационного и портового типа, создаваемых в соответствии с Федеральным законом «Об особых экономических зонах» от 22 июля 2005 г. №116-Ф3, а также технопарков, создание которых осуществляется в рамках реализации государственной программы «Создание в Российской Федерации технопарков в сфере высоких технологий», одобренной распоряжением Правительства Российской Федерации от 10 марта 2006 г. № 328-р.

Значимость судостроения и судоремонта для России объясняется в первую очередь географическим положением: страна имеет почти 40 тыс. км морской границы и 100 тыс. км внутренних водных путей. Значительная доля внешней торговли обслуживается морским транспортом. «Эффективные механизмы финансирования проектов развития кластеров сформированы в результате образования и деятельности ряда институтов развития, включая Инвестиционный фонд Российской Федерации, государственную корпорацию «Банк развития и внешнеэкономической деятельности (Внешэкономбанк)», ОАО «Российская венчурная компания», Фонд содействия развитию малых форм предприятий в научно-технической сфере» [1]. Судостроительная промышленность в значительной мере определяет национальную безопасность государства во всех сферах морской деятельности России, в том числе, оборонной, транспортной, продовольственной, энергетической и технологической. «Территориальные кластеры (далее - кластеры) - объединение предприятий, поставщиков оборудования, комплектующих, специализированных производственных и сервисных услуг, научноисследовательских и образовательных организаций, связанных отношениями территориальной близости и функциональной зависимости в сфере производства и реализации товаров и услуг. При этом кластеры могут размещаться на территории как одного, так и нескольких субъектов Российской Федерации» [2].

На данном этапе развития в отрасли для объединения наиболее ценных активов и повышения конкурентоспособности отечественного судостроения и судоремонта созданы интегрированные структуры - кластеры. Целью создания этих организаций являются управление, контроль, анализ и планирование деятельности научно-исследовательских и промышленных организаций, которые обеспечивают 
потребность государства в надводных кораблях и подводных лодках для Военно-морского флота, в производстве продукции гражданского назначения и морской техники для освоения континентального шельфа. Отечественное судостроение и судоремонт сегодня не в состоянии конкурировать с современными отраслевыми мировыми лидерами. К основным проблемам для предприятий судостроения и судоремонта Приморского края по предварительной оценке отнесены [3]:

- высокий уровень физического и морального износа основного и технологического оборудования;

- износ основных производственных фондов предприятий с использованием нормативов для крупных предприятий - не более $22 \%$, для средних - около $8 \%$, для малых - около $18 \%$;

- устаревшие технологические и проектные решения;

- острая нехватки и проблема старения квалифицированных кадров;

- уровень автоматизации производственных и управленческих процессов, отвечающих вопросам планирования, организации и технологии производства;

- конкуренция с соседними китайскими, корейскими и японскими верфями;

- недостаточность инвестиционных проектов, их экспертной оценки, отсутствие баз данных проектов потенциальных инвесторов.

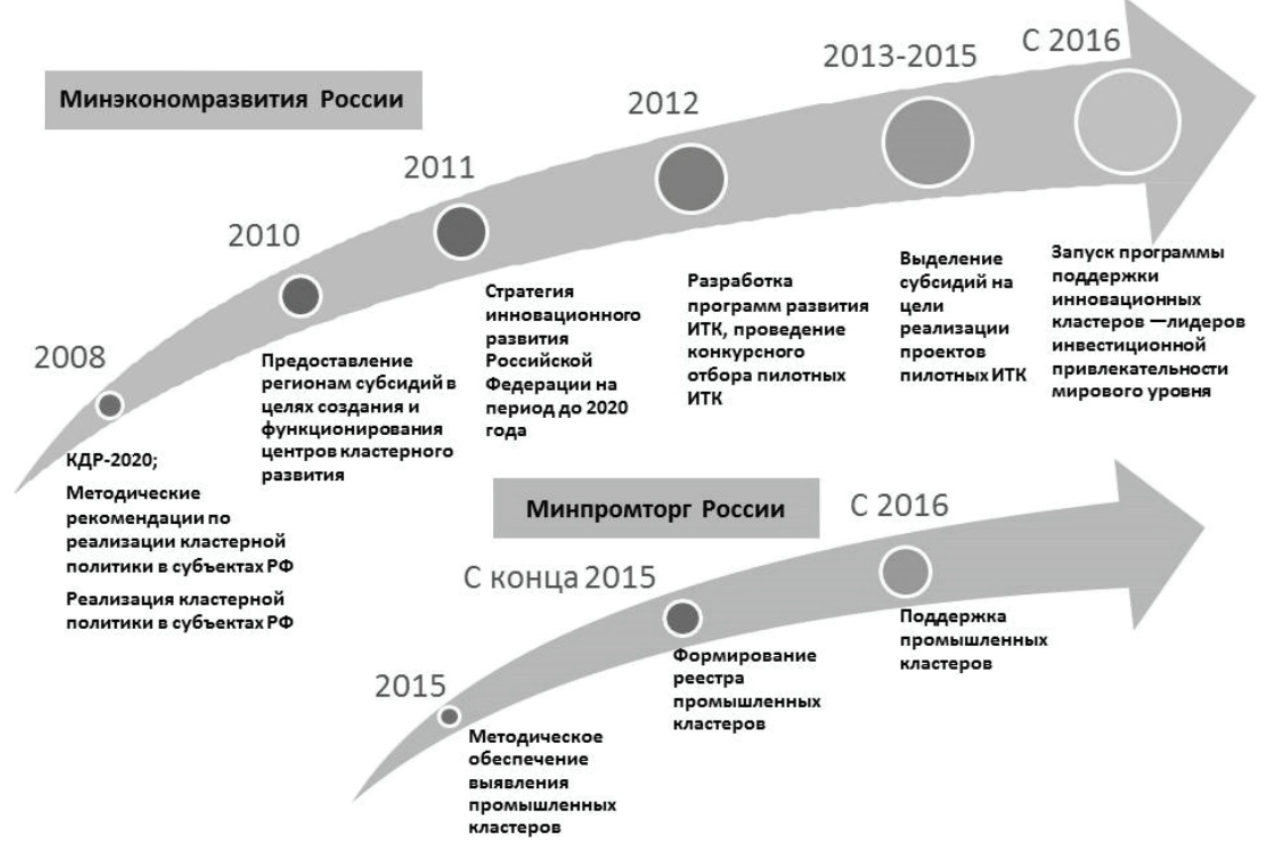

Рис. 1. Основные этапы реализации кластерной политики в России

По материалам Российской кластерной обсерватории на рис. 1 представлены основные этапы реализации кластерной политики. Причем описаны этапы только для двух направлений федерального уровня. Не представлены организация кластеров на региональном уровне и порядок их успешного функционирования, что объясняется особенностями отрасли экономики, самого региона, соседних с ним и т.д. [4].

Судостроительная и судоремонтная отрасли обладают достаточно высоким научно-техническим и производственным потенциалом, связаны с предприятиями 
смежных отраслей и национальной безопасностью во всех сферах морской деятельности государства. Для стратегически важного региона России - Приморского края - это очень актуально, поэтому необходимо поставить цель, позволяющую достичь очень важных результатов. Для этого следует выявить причины и возможности устранения отставания в конкуренции.

Основная часть производственных мощностей отечественного судостроения и судоремонта расположена на территории Северо-Западного федерального округа, что объясняется близостью к Балтийскому морю. Помимо этого, судостроение и судоремонт активно развиваются в последние годы в Приморском крае. Менее половины предприятий расположено в Северо-Западном регионе, при этом их объемы производства и кадровый потенциал составляют соответственно 70 и $60 \%$. Дальний Восток занимает по всем позициям неутешительное положение, но дополнить эти аналитические процедуры можно на основе сравнения этих характеристик (табл. 1). Оценка позволяет сделать такое обобщение: хотя Дальний Восток занимает последнее место по распределению предприятий судостроения и судоремонта, объему производства и наличию кадров, но соотношение показателей в расчете на отдельное предприятие не такое удручающее (предпоследнее место), причем это относится и к производственному эффекту деятельности предприятий.

Таблийа 1

\section{Соотношение показателей по регионам Российской Федерации}

\begin{tabular}{|l|c|c|c|c|}
\hline \multicolumn{1}{|c|}{ Показатель } & $\begin{array}{c}\text { Северо-западный } \\
\text { регион }\end{array}$ & Приволжье & $\begin{array}{c}\text { Дальний } \\
\text { Восток }\end{array}$ & $\begin{array}{c}\text { Прочие } \\
\text { регионы }\end{array}$ \\
\hline $\begin{array}{l}\text { Объемы производства/ } \\
\text { Количество предприятий }\end{array}$ & 1,67 & 0,80 & 0,57 & 0,34 \\
\hline $\begin{array}{l}\text { Кадровый потенциал/ } \\
\text { Количество предприятий }\end{array}$ & 1,43 & 0,80 & 0,71 & 0,62 \\
\hline
\end{tabular}

Примечание: Российская кластерная обсерватория [4].

Создание кластеров судостроения и судоремонта является стимулирующей базой для дальнейшего развития предприятий этого направления экономики в Приморском крае и городе Владивостоке. В Приморском крае на сегодняшний день существует 16 предприятий судостроения и судоремонта, среди них наиболее подготовленными к обновлению и развитию считаются такие предприятия, как ОАО ХК «Дальзавод» и ДВЗ «Звезда» [5] (табл. 2).

Виды деятельности судостроительных и судоремонтных предприятий Приморского края

\begin{tabular}{|l|l|}
\hline \multicolumn{1}{|c|}{ Название } & \multicolumn{1}{|c|}{ Вид деятельности } \\
\hline АО Дальнево- \\
$\begin{array}{l}\text { сточный завод } \\
\text { «Звезда» }\end{array}$ & $\begin{array}{l}\text { Ведущее предприятие по ремонту подводных лодок Тихоокеанского } \\
\text { рлоте и единственное на Дальнем Востоке специализирующееся на ре- } \\
\text { ракеносцев. Завод «Звезда» - хорошо оснащенный комплекс, облада- } \\
\text { ющий высоким техническим и производственным потенциалом, кото- } \\
\text { рый позволяет качественно и своевременно выполнять работы по всем } \\
\text { основным направлениям деятельности предприятия }\end{array}$ \\
\hline
\end{tabular}


Окончание табл. 2

\begin{tabular}{|l|l|}
\hline \multicolumn{1}{|c|}{ Название } & \multicolumn{1}{|c|}{ Вид деятельности } \\
\hline $\begin{array}{l}\text { АО Центр } \\
\text { судоремонта } \\
\text { «Дальзавод» }\end{array}$ & $\begin{array}{l}\text { Центр судоремонта «Дальзавод» является главной ремонтной базой } \\
\text { надводного и дизель-электрического подводного Флота России на Ти- } \\
\text { ту, изготовле Предприятием обеспечивается выполнение работ по ремон- } \\
\text { рулевого комплекса, судовых устройств и механизмов }\end{array}$ \\
\hline
\end{tabular}

Примечание: по данным официального сайта Дальневосточного Центра судостроения и судоремонта.

Для каждой из подсистем структурной модели управления реализацией стратегических планов должен быть сформирован «Каталог (перечень) показателей и допустимых или рекомендуемых значений, удовлетворяющий возможностям сравнения с конкурентами российскими и зарубежными» [6] (табл. 3).

Таблица 3

\section{Система показателей оценки конкурентоспособности предприятий} судостроительно-судоремонтной отрасли

\begin{tabular}{|l|l|}
\hline $\begin{array}{c}\text { Направления } \\
\text { подсистем }\end{array}$ & \multicolumn{1}{|c|}{ Показатель } \\
\hline Маркетинг & Коэффициент рыночной доли \\
\hline Финансы & $\begin{array}{l}\text { Рентабельность предприятия и капитала } \\
\text { Коэффициент текущей ликвидности } \\
\text { Общая рентабельность производственных фондов } \\
\text { Показатели эффективности использования финансовых средств }\end{array}$ \\
\hline Производство & $\begin{array}{l}\text { Состояние и эффективность использования основных фондов и } \\
\text { оборотных средств и их составляющих } \\
\text { Эффективность использования живых ресурсов предприятия } \\
\text { (производительность труда, средняя заработная плата по категориям) }\end{array}$ \\
\hline Персонал & $\begin{array}{l}\text { Качественные показатели кадровой составляющей (квалификация, стаж } \\
\text { работы) } \\
\text { Коэффициент стабильности кадров } \\
\text { Средняя заработная плата }\end{array}$ \\
\hline Управление & $\begin{array}{l}\text { Коэффициент маневренности } \\
\text { Рентабельностьпродукции (затраты нарубль реализованной продукции). } \\
\text { Интегральная эффективность предприятия (результат/ресурсы) }\end{array}$ \\
\hline Маркетинг & Коэффициент рыночной доли \\
\hline
\end{tabular}

Примечание: сост. авт.

Все представленные в таблице направления взаимосвязаны, характеризуют определенным образом влияние друг на друга и должны быть представлены экспертными заключениями по их использованию при формировании кластера. Такое взаимодействие формирования ключевых показателей и их значений на базе экспертных оценок предполагает формирование единой сопоставимой методики их расчета. Следует отметить, что подсистема «Производство» является главенствующей, так как в нее входят другие показатели эффективности деятельности предприятия и использования ресурсов (себестоимость, прибыль, рентабельность предприятия, продукции, средств и предметов труда, оснащенность основными фондами и т.д.). 
По данным кластерной обсерватории [4] гражданское судостроение в нашей стране развивалось слабо, за исключением нескольких сегментов отрасли, а именно: ледоколов, плавучих буровых установок, судов и кораблей на подводных крыльях и воздушной подушке. Структура судостроения и судоремонта в Приморском крае представлена на рисунке 2 , распределение предприятий практически одинаковое от 24 до $40 \%$.
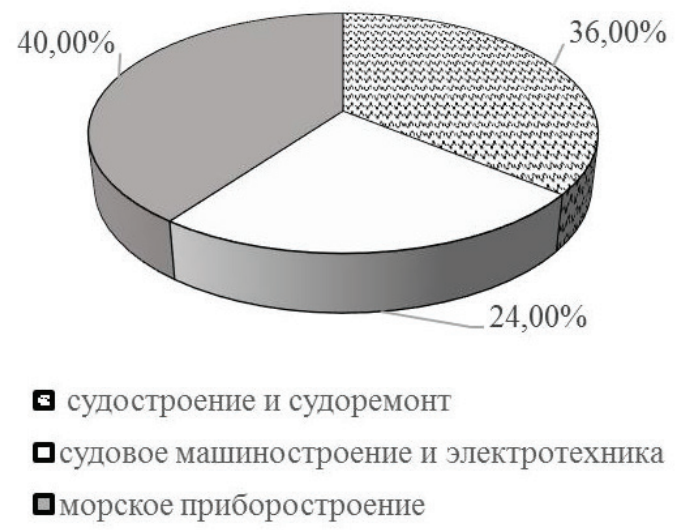

Рис. 2. Структура предприятий отрасли судостроения и судоремонта

Законодательной базой формирования кластеров служит итоговое совещание «О перспективах развития отечественного гражданского судостроения», где Президент РФ предлагал создать на Дальнем Востоке судостроительный промышленный кластер по производству морской техники и оборудования на базе ОАО «Дальневосточного центра судостроения и судоремонта» (ДЦСС). Основными задачами ДЦСС являются формирование судостроительного промышленного кластера на Дальнем Востоке России, реализация пилотного проекта кластера - создание судостроительного комплекса «Звезда», реализация ряда проектов по строительству судов гражданского назначения, по развитию судостроения и судоремонта в Дальневосточном федеральном округе. Проекты ДЦСС включают создание кластера на юге Приморья, строительство судостроительного комплекса «Звезда» и организацию центра профессиональной подготовки специалистов.

Построение развития судоремонтно-судостроительного комплекса должно базироваться на использовании научных методов, практически значимых для хозяйствующего субъекта $[3,6]$. Такое обоснование предполагает осуществление стратегических планов с учетом научных и законодательных мотиваций, учитывающих интересы по направлениям. Можно предложить основополагающие подходы при аналитических (оценочных) процедурах индикаторов, выделив направления и обозначив их характеристики, используя методику оценки рисков инновационного проекта: экспертный, маркетинговый, статистический. В подходе «экспертная оценка» среди показателей возможна оценка конкуренции с соседями (Южная Корея, Китай, Япония), потенциальных инвесторов, контроля использования инвестиций по прямому назначению и т.д.

Несмотря на то, что стратегический потенциал формирует преимущественно внутренние ресурсы предприятия, тем не менее, один из показателей, учитываемый при его определении, это положение предприятия на рынке, который должен 
использовать маркетинговый подход. Изучение конкурентов и своих позиций на рынке требуется предприятию для того, чтобы определить свои преимущества и недостатки и разработать собственную стратегию успеха и поддержания конкурентного преимущества.

Предлагаемый план мероприятий (табл. 4) содержит ориентировочные действия по достижению определенных целей для предприятий судостроения и судоремонта Приморского края [1] и может быть использован при формировании стратегических планов.

Таблициа 4

\section{План мероприятий по реализации стратегии социально-экономического развития Приморского края до 2025 года}

\begin{tabular}{|c|c|}
\hline \multicolumn{2}{|c|}{ Мероприятия } \\
\hline 2008-2012 гг. & 2012-2017 гг \\
\hline \multicolumn{2}{|c|}{$\begin{array}{l}\text { 1. Повышение конкурентоспособности базовых секторов экономики и формирования } \\
\text { эффективных кластеров }\end{array}$} \\
\hline \multicolumn{2}{|c|}{. } \\
\hline \multicolumn{2}{|l|}{ 1.6. Развитие судостроения и судоремонта } \\
\hline $\begin{array}{l}\text { 1. Создание Дальневосточного центра объеди- } \\
\text { ненной судостроительной корпорации }\end{array}$ & \multirow{5}{*}{$\begin{array}{l}\text { 1. Сопровождение реализации круп- } \\
\text { ных инвестиционных проектов. } \\
\text { 2. Стимулирование производства вы- } \\
\text { сокотехнологичной продукции (в том } \\
\text { числе создание современного техно- } \\
\text { парка) }\end{array}$} \\
\hline $\begin{array}{l}\text { 2. Поддержка действующих конструкторских } \\
\text { бюро }\end{array}$ & \\
\hline $\begin{array}{l}\text { 3. Развитие производственной инфраструктуры и } \\
\text { создание институциональных условий для при- } \\
\text { влечения стратегических инвесторов в отрасль }\end{array}$ & \\
\hline 4. Стимулирование модернизации производства & \\
\hline $\begin{array}{l}\text { 5. Развитие механизмов стимулирования } \\
\text { потребления }\end{array}$ & \\
\hline
\end{tabular}

Примечание: фрагмент документа «Стратегия социально-экономического развития Приморского края до 2025 года».

Неформальные объединения (кластеры) в судостроении и судоремонте с множеством крупных, малых и средних предприятий, технологических центров, проектно-конструкторских фирм, связующих рыночных институтов и потребителей, осуществляющих совместную деятельность, позволяют сформировать комплексный взгляд на государственную политику развития региона с учетом потенциала экономических субъектов Приморского края.

На сегодняшний день в законодательных актах регионального уровня отсутствуют документы, регулирующие работу кластера судостроения и судоремонта в Приморье, хотя есть достаточное количество научных разработок (моделей) по созданию кластера с предложениями его участников [4]. В качестве Центра кластера можно предложить Дальневосточный центр судостроения и судоремонта, объединяющий основные судоремонтные и судостроительные производственные мощности Дальневосточного федерального округа. На официальном сайте организации представлены задачи, среди которых обозначены формирование судостроительного промышленного кластера на Дальнем Востоке и реализация 
мероприятий по развитию судостроения и судоремонта в ДФО, организация центра профессиональной подготовки судостроителей.

Реализация подпрограммы «Развитие судостроительной науки» направлена на формирование государственных научных центров по решению проблем развития отечественного судостроения и развитие научно-технического задела в направлении морской техники военного и гражданского назначения с финансированием из средств федерального бюджета. Не менее важной задачей является решение кадровых проблем, так как демографический провал конца прошлого века стал определенной проблемой для подготовки и формирования высококвалифицированных и научных кадров для судостроения и судоремонта как для высокотехнологичных отраслей.

Очевидно, что в качестве объектов управления следует использовать кластеры как систему взаимосвязей фирм и организаций. В соответствии со структурированным подходом к построению технической, управленческой, социальной и маркетинговой стратегий и политики кластерного развития автором предлагается создание замкнуто-центрового контакта участников кластера, замкнутых на единый Центр ответственности [7, 8].

Обобщая результаты исследования, отметим, что предложенные рекомендации позволят решить основную часть проблем в создании эффективной стратегии российского судостроения и судоремонта на Дальнем Востоке с учетом всех проблем на основе логичного и последовательного алгоритма на базе наиболее подготовленных предприятий судостроения и судоремонта Приморского края:

- необходимость определенных сравнений с Южной Кореей, Китаем и Японией (наличие государственной поддержки, конкурентоспособность);

- создание стратегического плана по развитию на базе теоретических и законодательных подходов, кластеров, дифференцированного подхода к комплексному мониторингу процесса реализации планов на основе систем показателей, базирующихся на Единой методике и сопоставимости, ориентированной на повышение конкурентоспособности;

- осуществление практически значимого подхода для расчета диагностических и стратегических показателей.

1. О стратегии социально-экономического развития Приморского края до 2025 года [Электронный ресурc]. URL: https://elibrary.ru/download/elibrary_12510814_24652688.pdf

2. Государственная программа Российской Федерации «Развитие судостроения на 2013-2030 годы»: распоряжение Правительства РФ от 24.12.2012 № 2514-р (Об утверждении государственной программы Российской Федерации «Развитие судостроения на 2013-2030 годы») [Электронный ресурс]. URL: http://www.minpromtorg.gov.ru/reposit/ minprom/ministry/fcp/6/suda.doc

3. Астафурова И.С. Организационно-методические подходы к формированию стратегических планов на основе SWOT-анализа // Экономика и предпринимательство. 2016. № 10-2 (75-2). C. 1114-1118. 
4. Российская кластерная обсерватория [Электронный ресурс]. URL: http:/cluster.hse.ru

5. Дальневосточный центра судостроения и судоремонта [Электронный ресуpc]. URL: http://dcss.ru/osnovnyie-predpriyatiya/

6. Астафурова И.С. Оценка показателей, характеризующих способность предприятия к устойчивому развитию, как основа планирования // Экономика и предпринимательство. 2015. № 3 (56). С. 724-727.

7. Астафурова И.С. Реализация стратегии промышленного предприятия от замысла к результату // Азимут научных исследований: экономика и управление. 2018. Т. 7. № 1 (22). С. 26-30.

8. Судостроение России: Горизонты развития: Доклад экспертного совета Председателя ВПК при Правительстве РФ. Т.М. Гареев, С.А. Губкин, Б.С. Зулькарнаев, В.А. Лебедев и др. Москва, 2013 [Электронный ресурс]. URL: http://www.instrategy.ru/pdf/249.pdf

\section{Транслитерация}

1. O strategii sotsial'no-ekonomicheskogo razvitiya Primorskogo kraya do 2025 goda. URL: https://elibrary.ru/download/elibrary_12510814_24652688.pdf

2. Gosudarstvennaya programma Rossijskoj Federatsii «Razvitie sudostroeniya na 20132030 gody». Rasporyazhenie Pravitel'stva RF ot 24.12.2012 N 2514-r (Ob utverzhdenii gosudarstvennoj programmy Rossijskoj Federatsii «Razvitie sudostroeniya na 2013-2030 gody»). URL: Rezhim dostupa: http://www.minpromtorg.gov.ru/reposit/minprom/ministry/ fcp/6/suda.doc

3. Astafurova I.S. Organizatsionno-metodicheskie podhody k formirovaniyu strategicheskih planov na osnove SWOT- analiza, Ekonomika i predprinimatel'stvo, 2016, No 10-2 (75-2), pp. 1114-1118.

4. Rossijskaya klasternaya observatoriya. URL: http://cluster.hse.ru

5. Ofitsial'nyj sajt Dal'nevostochnogo Tsentra sudostroeniya i sudoremonta. URL: http://dcss. ru/osnovnyie-predpriyatiya/

6. Astafurova I.S. Otsenka pokazatelej, harakterizuyuschih sposobnost' predpriyatiya k ustojchivomu razvitiyu, kak osnova planirovaniya, Ekonomika i predprinimatel'stvo, 2015, No 3 (56), pp. 724-727.

7. Astafurova I.S. Realizatsiya strategii promyshlennogo predpriyatiya ot zamysla k rezul'tatu, Azimut nauchny issledovanij: ekonomika i upravlenie, 2018, vol. 7, No 1 (22), pp. 26-30.

8. Sudostroenie Rossii: Gorizonty razvitiya / Gareev T.M., Gubkin S.A., Zul'karnaev B.S., Lebedev V.A., Kramnik I.A., Chetvertakov M.M. Doklad ekspertnogo soveta Predsedatelya VPK pri Pravitel'stve RF. Moskva, 2013. URL: http://www.instrategy.ru/pdf/249.pdf

\section{(С) И.С. Астафурова, 2018}

Для цитирования: Астафурова И.С. Кластер судостроения и судоремонта Приморского края: перспективы и возможности // Территория новых возможностей. Вестник Владивостокского государственного университета экономики и сервиса. 2018. Т. 10. № 2. С. 28-36.

For citation: Astafurova I.S. Cluster of shipbuilding and ship repair in Primorsky Region: prospects and opportunities, The Territory of New Opportunities. The Herald of Vladivostok State University of Economics and Service, 2018, Vol. 10, No 2, pp. 28-36.

DOI dx.doi.org/10.24866/VVSU/2073-3984/2018-2/028-036

Дата поступления: 13.04.2018. 